\title{
Successful treatment of a heart mate ii left ventricular assist device thrombus in the setting of a massive acute stroke: a case report and review of the literature
}

\begin{abstract}
Left ventricular assist devices (LVADs) are increasingly used to treat patients with advanced heart failure both as a Bridge-To-Cardiac Transplantation and Destination Therapy. Device thrombosis is a well-known complication of LVADs that can be potentially catastrophic if not diagnosed early and appropriately managed. We present a case of successful treatment of a suspected Heart Mate II thrombus with systemic thrombolysis and Eptifibatide in a patient who presented with signs and symptoms of acute decompensated heart failure and an ischemic stroke. We further compiled published case reports on acute thrombosis management in contemporary continuous flow LVADs, to discern various treatment approaches available for this serious complication. Published research on optimal anticoagulation management strategy in the setting of acute device thrombosis is limited, primarily due to the size of this cohort but also due to the nuances involved in tracking such data. We would like to suggest that all potential device thrombosis cases and their management be reported to a registry or added to a existing registry such as INTERMCAS (Interagency Registry for Mechanically Assisted Circulatory Support), as this would not only enhance our understanding on this topic but also serve as a building block for future research and could be used to make evidence based management recommendations.
\end{abstract}

Keywords: left ventricular assist device, thrombus, thrombolysis, management, recommendations
Volume I Issue 7 - 2014

\author{
Ajay V Srivastava,' Marta Nalbandyan DO, ${ }^{2}$ \\ Dan Richard Branch RN, ${ }^{3}$ Pervaiz Chaudry, ${ }^{4}$ \\ John Chin ${ }^{4}$ \\ 'Division of Cardiovascular Medicine, Scripps Clinic, USA \\ ${ }^{2}$ Department of Internal Medicine, University of California San \\ Francisco Fresno, USA \\ ${ }^{3}$ Cardiothoracic Surgery, Community Regional Medical Center, \\ USA \\ ${ }^{4}$ Heart and Vascular Center, Sutter Medical Center, USA
}

Correspondence: Ajay V Srivastava, Comprehensive Heart Failure \& Mechanical Circulatory Assist Device Program, Heart Failure Recovery \& Research Program, Pulmonary Hypertension Program, Scripps Clinic Torrey Pines, 10666 N, Torrey Pines Road, SW206, La Jolla, CA 92037, USA, Tel 858-554-5588, Email srivastava.ajay@scrippshealth.org

Received: November 25, 2014 | Published: November 27, 2014

\section{Case report}

A 56-year-old Caucasian male with a cardiac history of severe nonischemic cardiomyopathy, 3months post Heart Mate II (Thoratec, Pleasanton, CA) Left ventricular Assist Device (LVAD) implantation, presented to the hospital with a history of acute difficulty in breathing, lethargy and decreased mentation per his wife. He was transferred from an outside hospital about 5 hours since presenting there and during which time he was treated for acute heart failure with intra-venous furosemide. On examination, he was found to be in severe respiratory distress and semi- obtunded. On physical exam he had significant right hemiplegia that was not reported from the outside hospital. A "Stroke Code" was called and a stat- non-contrast-enhanced CT brain was ordered. On connecting his LVAD to the base power module, his parameters were: RPM 10,000, Power-12, Pulsatility Index-2.1, and Flow-3-4 L/min, (Table 1). The higher power and low PI readings in the setting of acute heart failure immediately raised the suspicion of an acute device thrombus. His wife told us that patient's symptoms of shortness of breath, dizziness and an episode of fall with no loss of consciousness had started about 4 hours prior to presentation at the outside hospital and about 9 hours prior to presentation at our hospital.

His past medical history was significant for episodes of gastrointestinal bleeds secondary to small bowel AV fistulas, postmitral valve repair, and right total knee arthroplasty with chronic infection that required long-term Dicloxacillin therapy. His outpatient anti-coagulation regimen was Aspirin 325mg daily and Warfarin with a goal INR of 1.5-2. Due to recurrent episodes of GI bleeds his recent INR goal was between 1.5-2. On presentation patients INR was 1.6. His other medications included Amiodarone 200mg daily, Carvedilol
$3.125 \mathrm{mg}$ twice daily, Isordil mononitrate $30 \mathrm{mg}$ daily, Ferrous Sulfate $324 \mathrm{mg}$ twice daily, Bumetanide $1 \mathrm{mg}$ daily, Dicloxacillin 500mg twice daily, Allopurinol $300 \mathrm{mg}$ daily, Pantoprazole $40 \mathrm{mg}$ daily, Tramadol 200mg daily, Hydrocodone-Acetaminophen 10-325 three times daily and Zolpidem 10mg nightly.

Vital signs on presentation at the outside hospital were: Temperature 38.1 F, Heart Rate of 90-101 beats/minute, Respiratory Rate 20-40 breaths/ minute, mean arterial pressure of $70 \mathrm{mmHg}$ and oxygen saturation of $94 \%$ on VentiMask $40 \%$. On examination at our hospital he was found to be tachypneic at 33 breaths/minute requiring Bilevel positive airway pressure (BiPAP), heart rate-106 beats/minute, mean arterial pressure- $64 \mathrm{mmHg}$ and oxygen saturation of $90 \%$ on VentiMask 40\%. He appeared confused and lethargic. Neck exam was positive for jugular venous distension. He had decreased breath sounds bilaterally and the LVAD hum was heard on cardiac exam. On neurologic exam, he did not follow any commands, was aphasic with a right facial droop and had right hemiplegia. On checking with the outside hospital, due to his acute distress and lethargy, a neurologic exam was not performed. Laboratory tests on admission were consistent with hemolysis and acute renal failure (Table 2). LDH was elevated at 3012 (IU/L) up from $<500$ a week ago. Chest radiography was consistent with pulmonary edema (Figure 1). CT Head revealed a left non-hemorrhagic MCA infarct with mild mass effect and mild midline shift from left to right (Figure 2). Urine in his Foley bag was orange- red in color. A stat echocardiogram (Figure 3 ) obtained revealed a dilated left and right ventricle and an aortic valve opening every beat that was opening every other beat on his last clinic visit, 3 weeks ago. This further confirmed the working diagnosis of 
an acute LVAD thrombus complicated by an embolic event leading to the acute ischemic infarct. An emergent Neurology consultation was obtained and after reviewing his physical exam and CT-brain with the Neurology team, the diagnosis of acute ischemic stroke with significant right hemiplegia was confirmed. Since he was outside the recommended treatment window for thrombolytic administration for his acute stroke (9hours against the recommended, the Neurology team recommended against the use of systemic thrombolysis due to the increased risk for bleeding vs. reducing infarct size.

a) Patient was started on intravenous Furosemide (--mg/ dl) and Milrinone at $0.5 \mathrm{mcg} / \mathrm{kg} /$ minute for inotropic support. After considering various management approaches including

b) Treating the potential LVAD thrombus with systemic thrombolysis while monitoring his neurologic status. Treating him conservatively with no immediate anticoagulation and supporting his cardiac function with inotropes until the completion of his infarct.

c) Treating the potential LVAD thrombus with catheter directed thrombolysis and d) LVAD pump exchange we decided to proceed with systemic thrombolysis.

He was administered a recombinant tissue plasminogen activator, Alteplase $70 \mathrm{mg} \mathrm{IV} \mathrm{X} 1(0.81 \mathrm{mg} / \mathrm{kg}$ x $86.2 \mathrm{~kg})$ over 1 minute, followed by $7.7 \mathrm{mgs}(0.09 \mathrm{mg} / \mathrm{kg} \times 86.2 \mathrm{~kg})$. His LVAD parameters post-Alteplase infusion were: RPM- 10,000, Power- 7.7, Pulsatility index-3.5, Flow-6.4 L/min. 24-hours post completion of Alteplase infusion; he was started on intra-venous Heparin continuous infusion (--units) with no bolus. CT-Head scans were obtained serially, prior to initiating heparin therapy and during the $1^{\text {st }}$ week and showed evolving ischemic infarct with no intra-cranial hemorrhage (Figure 4). On day 4 with no further decrease in his LVAD power (Table 1) he was started on a continuous infusion of Eptifibatide at $1 \mathrm{mcg} / \mathrm{kg} / \mathrm{min}$ that was increased to $1.5 \mathrm{mcg} / \mathrm{kg} / \mathrm{min}$ for days 6,7 and continued at $1 \mathrm{mg} / \mathrm{kg} / \mathrm{min}$ for days $8-19$. During this time his hemodynamics also improved allowing inotropic support with Milrinone to be weaned off. CT-Head performed on day 16 showed completed ischemic infarct with small stable sub-arachnoid hemorrhage (Figure 5).

On day 19 an echocardiogram performed showed a less dilated LV and an aortic valve that was opening every other beat. At this point he was transitioned back from Eptifibatide infusion to continuous IV Heparin infusion. His LVAD powers had also decreased during this period compared to admission (Table 1). On day 24 Warfarin therapy was initiated aiming for an INR goal of 2-2.5. Aggressive physical therapy was continued all along. On day 29 he was discharged to inpatient rehab. On day 48 he was discharged home from inpatient rehab on an anti-coagulation regimen that included Aspirin $325 \mathrm{mg}$ once dailyand Warfarin (INR goal-2-2.5). On his most recent visit to the LVAD clinic which was day 70 since his initial presentation with the acute stroke, he is able to speak and walk without any assistance or aids. He has mild residual dysphagia but is able to tolerate oral feeds and otherwise has no complaints. His LVAD parameters have returned to baseline (Table 1). He is currently listed and awaiting cardiac transplantation.

Table I LVAD Parameters. LVADs, left ventricular assist devices; RPMs, revolutions per minute

\begin{tabular}{llllllll}
\hline & $\begin{array}{l}\text { Day I- } \\
\text { Admission }\end{array}$ & Day 3 & Day 7 & Day 19 & $\begin{array}{l}\text { Day 29- } \\
\text { Discharged to Rehab }\end{array}$ & $\begin{array}{l}\text { Day 29- } \\
\text { Discharged to Home }\end{array}$ & $\begin{array}{l}\text { Day 70- } \\
\text { Current }\end{array}$ \\
\hline LVAD RPM & 10,000 & 10,000 & 9800 & 10,000 & 9600 & 9600 & 9600 \\
LVAD Power & 12 & 7.7 & 7.5 & 7 & 7 & 7 & 6.4 \\
LVAD Flow & $03-\mathrm{Apr}$ & 6.4 & 6.4 & 6 & 5.6 & 5.8 & 5.3 \\
LVAD Pulsatility Index & 2.1 & 3.5 & 3.5 & 5.3 & 5.3 & 4.8 & 5.4 \\
MAP (mmHg) & 64 & 80 & 70 & 68 & 96 & 88 & 78 \\
\hline
\end{tabular}

Table 2 Laboratory values

\begin{tabular}{|c|c|c|c|c|c|c|}
\hline & Day I- & Day 3 & Day 7 & Day 19 & Day 29- & Day 70- \\
\hline & \multicolumn{4}{|c|}{ Admission } & Discharged to Rehab & Current \\
\hline Hemoglobin $(\mathrm{g} / \mathrm{dl})$ & 7.6 & 8.8 & 8.8 & 8.4 & 8.7 & 8.9 \\
\hline Hematocrit (\%) & 23.8 & 29.8 & 25.7 & 26.8 & 24.8 & 28.2 \\
\hline Platelets (K/uL) & 94 & 109 & 111 & 86 & 139 & 204 \\
\hline LDH (IU/L) & 3012 & 2726 & 2236 & 12126 & 363 & 292 \\
\hline \multicolumn{7}{|l|}{ Plasma free hemoglobin } \\
\hline Haptoglobin (IU/L) & $<8$ & $<8$ & $<8$ & $<8$ & $<8$ & \\
\hline Total Bilirubin (mg/dl) & 1.8 & 2 & I.I & 0.4 & 0.3 & 0.4 \\
\hline Creatinine (mg/dl) & 1.8 & 1.3 & 1.4 & 0.7 & 1 & 0.9 \\
\hline
\end{tabular}




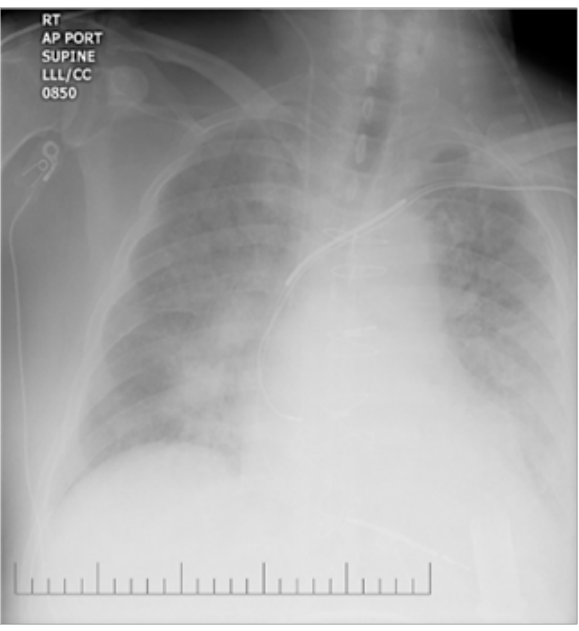

Figure I Chest X- Ray at presentation.

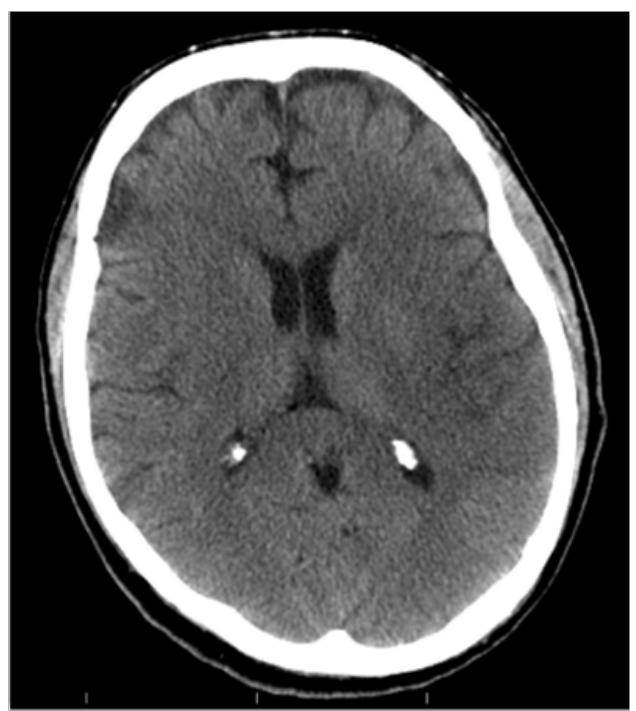

Figure 2 CT- Head at Presentation. Large left non- hemorrhagic middle cerebral artery infarct with mild mass effect.

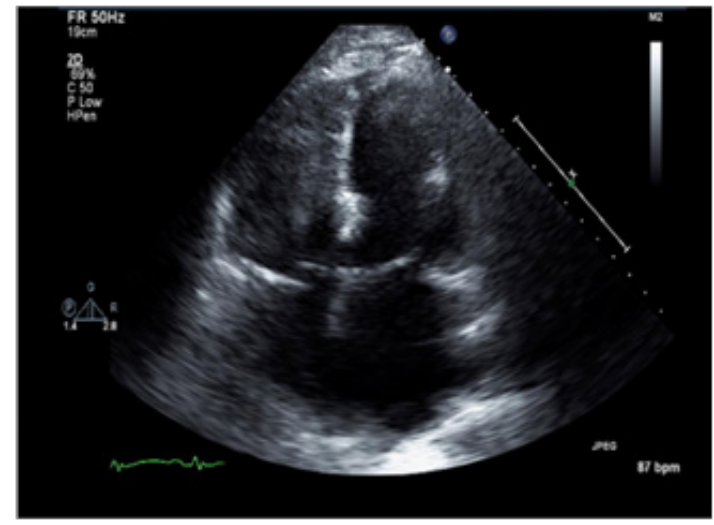

Figure 3 Echo- at Presentation. Apical-4 chamber view showing a dilated left and right ventricle despite increasing the Ivad rpm.

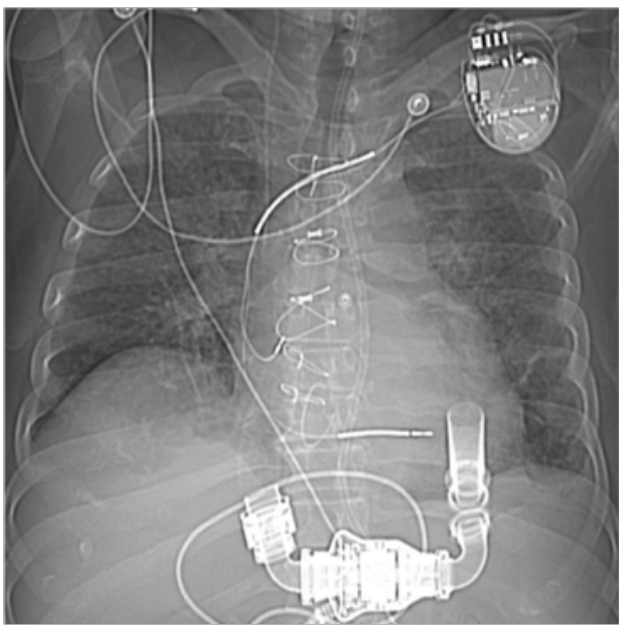

Figure 4 Chest- $X$ Ray Post- Thrombolytic Infusion showing

a) Decreased pulmonary vascular congestion

b) Unchanged LVAD cannula position from baseline

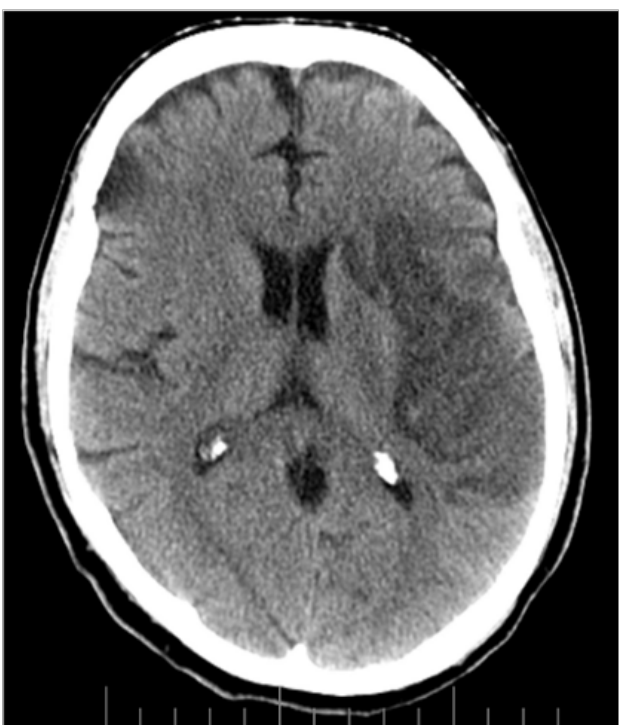

Figure 5 CT- head at 2 weeks- completed left middle cerebral artery infarct with a small stable subarachnoid hemorrhage.

\section{Discussion}

Despite the substantial survival benefit associated with LVADs, there is considerable morbidity and mortality associated with LVADs. Device thrombosis and cerebrovascular disease are known feared complications of LVADs. ${ }^{1,2}$ But in the last decade, with increasing clinical experience with LVADs, better patient selection and improved understanding of anti-coagulation management, device thrombosis and stroke rates have decreased considerably. ${ }^{3}$ Yet, as seen with the patient in this report and other anecdotal reports (Table 3), device thrombosis still occurs. In a scenario such as with our patient, management is particularly complicated as the patient presented with a clinical picture highly suggestive of a LVAD thrombus complicated by an acute ischemic infarct.

1. Prior to deciding on systemic thrombolysis with Alteplase, we had also considered. 
2. Catheter based direct thrombolysis.

3. Continuous Eptifibatide or Heparin infusion.
4. LVAD exchange, as these are all management approaches that have been used for treating acute LVAD thrombus (Table 3).

Table 3 Examples of Thrombus Treatment Regimens with Contemporary continuous flow LVADs Reported in the Literature.M- male; F- female; y/o- years old; HW, Heartware; HM II, HeartMate II; LVAD, Left ventricular assist device, INR, International normalized ratio; PTT, Partial thromboplastin time; LDH, Lactate dehydrogenase; IV, Intra-venous; LD, Loading dose.*Plasma free hemoglobin was checked. Was 0.86 g/liter, an increase from 0.08 g/liter checked 24 hours prior. Peaked at $2.7 \mathrm{~g} /$ liter and normalized at $0.10 \mathrm{~g} /$ liter by Day\# .

\begin{tabular}{|c|c|c|c|c|c|}
\hline $\begin{array}{l}\text { Author, Year of } \\
\text { publication }\end{array}$ & Age, Sex & $\begin{array}{l}\text { Device } \\
\text { Make }\end{array}$ & $\begin{array}{l}\text { Number of days post- LVAD } \\
\text { implantation at presentation, } \\
\text { postulated explanation for device } \\
\text { thrombosis }\end{array}$ & Initial LDH IU/L & Treatment regimen \\
\hline Tang et al. ${ }^{9}$ & $51 \mathrm{y} / 0 \mathrm{M}$ & HM II & Day\#I 50 Not reported & & $\begin{array}{l}\text { Catheter directed-Alteplase } 20 \\
\mathrm{mg} \text { f/b Alteplase } 80 \mathrm{mg} \text { IV over } 90 \\
\text { minutes }\end{array}$ \\
\hline Kamouh et al. ${ }^{10}$ & 62 y/o M & $\mathrm{HW}$ & Day\#I8 Sub-therapeutic INR (I.5) & 2400 & $\begin{array}{l}\text { Catheter directed-Alteplase } 1 \mathrm{mg} / \mathrm{min} \text {, } \\
\text { total } 30 \mathrm{mg}\end{array}$ \\
\hline Jennings et al. ${ }^{\prime \prime}$ & 44 y/o M & HM II & Day\#|21 & 3665 & $\begin{array}{l}\text { Eptifibatide } 1 \mathrm{mcg} / \mathrm{kg} / \mathrm{min} \times 4 \text { days } \mathrm{f} / \\
\text { bAspirin and Clopidogrel daily }\end{array}$ \\
\hline $\begin{array}{l}\text { Al-Quthami et } \\
\text { al. }{ }^{12}\end{array}$ & 66 y/o M & HM II & Day\#33 Sub-therapeutic INR (I.4) & 2326 & $\begin{array}{l}\text { Heparin } \times 5 \text { days, } \mathrm{f} / \mathrm{b} \text { Eptifibatide } \\
180 \mu \mathrm{g} / \mathrm{kg} / \mathrm{min} \mathrm{f} / \mathrm{bl} \mu \mathrm{g} / \mathrm{kg} / \mathrm{min}\end{array}$ \\
\hline $\begin{array}{l}\text { Al-Quthami et } \\
\text { al. }{ }^{12}\end{array}$ & $25 \mathrm{y} / \mathrm{oF}$ & HM II & Day\#33Sub-therapeutic INR (I.4) & 1292 & $\begin{array}{l}\text { IV Heparin (PTT 60-80) Eptifibatide } \\
\text { I } 80 \mu g / \mathrm{kg} / \mathrm{minf} / \mathrm{b} 2 \mu \mathrm{g} / \mathrm{kg} / \mathrm{min} \text { for } 4 \\
\text { days. Warfarin INR }(1.5-2.5)\end{array}$ \\
\hline Bashir et al. ${ }^{13}$ & $48 \mathrm{y} / \mathrm{oF}$ & HMII & Day \#3 Not reported & & - \\
\hline Kiernan et al. ${ }^{14}$ & 57 y/o M & HW & Day\#I50 Sub- therapeutic INR (I.4) & & $\begin{array}{l}\text { Catheter directed-Alteplase - I mg/ } \\
\text { min (total dose not reported) }\end{array}$ \\
\hline $\begin{array}{l}\text { Paluszkiewicz et } \\
\text { al. }{ }^{15}\end{array}$ & $68 \mathrm{y} / \mathrm{o} M$ & HM II & Day\#30 Not reported & áá & Lytic therapy (regimen not reported) \\
\hline Bhamidipati et al. ${ }^{16}$ & $6 \mathrm{l} / \mathrm{or}$ & HM II & $\begin{array}{l}\text { Day\#I } 8 \text { Excessive early post-operative } \\
\text { bleeding requiring multiple blood } \\
\text { product transfusions }\end{array}$ & $>2000$ & $\begin{array}{l}\text { Warfarin }(I N R>2.0) \text { after LVAD } \\
\text { exchange }\end{array}$ \\
\hline Thomas et al. ${ }^{.7}$ & 38 y/o F & $\mathrm{HW}$ & Day\#I40 Not reported & - & $\begin{array}{l}\text { IV Heparin f/b Tirofiban } 0.1 \mu \mathrm{g} / \mathrm{kg} / \mathrm{min} \text {, } \\
\text { ASA } 150 \mathrm{mg} \text { Clopidogrel } 600 \mathrm{mg} \text { LD, } \\
75 \mathrm{mg} \text { and Warfarin INR-2.5-3.5 }\end{array}$ \\
\hline Meyer et al. ${ }^{18}$ & 40 y/o M & HM II & Day\#60 Sub-therapeutic INR & & IV Hirudin PTT $50-60$ for 18 days \\
\hline
\end{tabular}

For our patient, after having a family meeting with the Neurology and LVAD teams and discussing the pros and cons of various treatment options including the risk of hemorrhagic conversion with administration of systemic thrombolysis outside the,, 4 hour window, a decision was made to proceed with systemic thrombolysis. We felt in the setting of an acute stroke, it would be extremely high risk to subject the patient to a device exchange surgery. Regarding Eptifibatide or Heparin infusion, we felt that with significant LVAD power consumption, acute decompensated heart failure, and massive ischemic stroke likely due to embolic source, the patient had an obstructive LVAD thrombus that would require thrombolysis and if left untreated he would be at an extremely high risk for another neurologic event and worsening heart failure.

After administering systemic thrombolysis at presentation, discussions were again held during the course of his hospital course regarding LVAD pump exchange as well as activating him for cardiac transplant but with persistent significant neurologic deficit, we felt he was too critical to undergo a surgery. Also, since he had a good clinical response to systemic thrombolysis with the pump power returning to baseline, resolved acute heart failure decomposition and renal function returning to baseline, we decided to mange him with aggressive anticoagulation and allow him time to recover from the 
acute stroke before he would be listed for cardiac transplantation or pump exchange. 1 month after his initial presentation he was discharged from the hospital to a rehabilitation facility with his anticoagulation regimen consisting of Aspirin 325mg daily and Warfarin therapy (goal INR 2-2.5). 2weeks later he was discharged home. Most recently he was seen at clinic, about 2.5 months since his acute presentation. He has had no high power alarms on his LVAD or heart failure decomposition episodes. His right hemiplegia has completely resolved with only mild residual dysphagia. He is currently listed and awaiting cardiac transplantation. While our patient had an excellent outcome considering his grave presentation, it again brings up the issue of optimal management of an acute LVAD thrombus. We performed a comprehensive literature search using PubMed, to identify case reports ${ }^{4-18}$ that relate to thrombus management in patients with continuous flow LVADs. Keywords used for the search included left ventricular assist devices, thrombosis, thrombolytic, Heart Mate II and Heart ware. While we acknowledge that this list (Table 3) is not exhaustive and may not include every published report on acute management of LVAD thrombosis, it certainly illustrates the varying management approaches applied in this situation. Currently it is not clear to care providers if one approach is better than the other (systemic thrombolytic vs. catheter directed thrombolysis vs. LVAD exchange vs. aggressive oral anti-coagulant and anti-platelet therapy) and how mortality and morbidity rates compare between these different approaches. Since LVADs are being more frequently used in treating patients with advanced heart failure, it is crucial for us to gain a better understanding on this serious acute complication. Currently about 150 medical centers participate in the INTERMACS registry that tracks MCS outcomes. Mandating that all LVAD implantation centers (bridge-to-transplant or destination therapy centers) participate in a registry such as this and report complications including patient management in the case of a potential LVAD thrombus would greatly add to our understanding of this very serious complication.

\section{Conclusion}

We believe this can be achieved by expanding the coordinated effort between LVAD implanting centers, NHLBI, CMS, ISHLT and LVAD manufacturers.

\section{Acknowledgments}

None.

\section{Conflicts of interest}

Authors declare that there is no conflict of interest.

\section{References}

1. Miller LW, Pagani FD, Russell SD, et al. Heart Mate II Clinical Investigators: Use of a continuous flow device in patients awaiting heart transplantation. N Engl J Med. 2007;357(9):885-896.

2. Slaughter MS, Rogers JG, Milano CA, et al. HeartMate II Investigators: Advanced heart failure treated with continuous-flow left ventricular assist device. N Engl J Med. 2009;361(23):2241-2251.
3. Birks EJ, Tansley PD, Yacoub $\mathrm{MH}$, et al. Incidence and clinical management of life-threatening left ventricular assist device failure. $J$ Heart Lung Transplant. 2004;23(8):964-969.

4. Rothenburger M, Wilhelm MJ, Hammel D, et al. Treatment of thrombus formation associated with the MicroMedDeBakey VAD using recombinant tissue plasminogen activator. Circulation. 2002;106(suppl I):I189-I192.

5. Studer MA, Kennedy CE, Dreyer WJ, et al. An alternative treatment strategy for pump thrombus in the DeBakey VAD Child: use of clopidogrel as a thrombolytic agent. $J$ Heart Lung Transplant. 2006;25(7):857-861.

6. Delgado R, Frazier OH, Myers TJ, et al. Direct thrombolytic therapy for intraventricular thrombosis in patients with the Jarvik 2000 left ventricular assist device. J Heart Lung Transplant. 2005;24(2):231-233.

7. Hayes H, Dembo L, Larbalestier R, et al. Successful treatment of ventricular assist device associated ventricular thrombus with systemic tenecteplase. Heart Lung Circ. 2008;17(3):235-255.

8. Boyle AJ, Russell SD, Teuteberg JJ, et al. Low thromboembolism and pump thrombosis with the HeartMate II left ventricular assist device:Analysis of outpatient anti-coagulation. J Heart Lung Transplant. 2009;28(9):881-887.

9. Al-Quthami AH, Jumean M, Kociol R, et al. Eptifibatide for the Treatment of HeartMate II Left Ventricular Assist Device Thrombosis. Circ Heart Fail. 2012;5(4):e68-e70.

10. Thomas MD, Wood C, Lovett M, et al. Successful treatment of rotary pump thrombus with the glycoprotein IIb/IIIa inhibitor tirofiban. $J$ Heart Lung Transplant. 2008;27(8):925-927.

11. Bhamidipati CM, Ailawadi G, Bergin J, et al. Early thrombus in a Heart Mate II left ventricular assist device: A potential cause of hemolysis and diagnostic dilemma. J Thorac Cardiovasc Surg. 2010;140(1):e7-e8.

12. Meyer AL, Kuehn C, Weidemann J, et al. Thrombus formation in a HeartMate II left ventricular assist device. J Thorac Cardiovasc Surg. 2008;135(1):203-204

13. Kamouh A, John R, Eckman P. Successful Treatment of Early Thrombosis of Heart Ware Left Ventricular Assist Device With Intraventricular Thrombolytics. Ann Thorac Surg. 2012;94(1):281-283.

14. Kiernan MS, Pham DT, DeNofrio D, et al. Management of Heart Ware left ventricular assist device thrombosis using intracavitary thrombolytics. $J$ ThoracCardiovasc Surg. 2011;142(3):712-714.

15. Jennings DL, Cabrera R, Wang DD, et al. Successful Treatment of a Continuous Flow Left Ventricular Assist Device Thrombosis With Eptifibatide. ASAIO J. 2012;58(6):633-635.

16. Tang GHL, Kim MC, Pinney SP, et al. Failed Repeated Thrombolysis Requiring Left Ventricular Assist Device Pump Exchange. Catheter Cardiovasc. 2003; Interv 81(6):1072-1074.

17. Paluszkiewicz L, Gursoy D, Spiliopoulos S, et al. HeartMate II ventricular assist device thrombosis-an echocardiographic approach to diagnosis:Can Doppler evaluation of flow be useful? $J$ Am Soc Echocardiogr. 2011;24(3):350,e1-e4.

18. Bashir J, Cheung A, Kaan A, et al. Thrombosis and failure of a Heart Mate II Device in the absence of alarms. J Heart Lung Transplant. 2011;30(10):1197-1199. 